\title{
ENTREPRENEURSHIP, EXOGENOUS CHANGE, AND THE FLEXIBILITY OF CAPITAL
}

\author{
Steven Horwitz ${ }^{\circ}$
}

\section{Introduction}

Over the course of his decades of contributions to Austrian economics, Israel Kirzner has enormously enhanced our understanding of the market process by his patient and detailed explorations of the fundamental concepts of microeconomics. Of those fundamentals, the areas of entrepreneurship and capital are two in which he has made ongoing and important contributions. In this essay, I hope to explore the intersection between those two fundamental areas of inquiry by taking a Kirznerian approach to why some firms are better able than others to respond to exogenous change. I want to argue that the ability to respond to such change is rooted in the capital structure, including the human capital, of firms and that entrepreneurial alertness requires a capital structure with certain attributes in order for such altertness to be "operationalized" in the organizational structure we call the firm.

To be somewhat more concrete: often times critics of the market argue that which firms prospser, is just a matter of "luck" or being at the right place at the right time when the market changes in a way that benefits those actors. On the obverse side, the same critics say that those who lose out in the face of detrimental changes in exogenous circumstances were victims of "bad luck" and those who do survive were just "lucky." Kirzner's theory of entrepreneurship provides the core of an answer to these critics by arguing that entrepreneurial profit is not just the result of luck, but it is not due to deliberate choice either. Rather good entrepreneurs are "alert" to profit possibilities. Alertness sits, as Kirzner has argued, between luck and deliberate search.

\footnotetext{
- Associate Professor of Economics, Associate Dean of the First Year, Whitman Hall, St. Latvrence University, Canton, NY 13617, enail sghorwitz@stlawu.edu
}

Volume 12, numéro 1, Mars 2002, pp 67-77. 
When dealing with the firm, however, the question becomes more complicated. What does it mean for a firm to be "alert?" Are we speaking only of the individuals who comprise it being alert, or are there ways in which an organization can be "corporately" alert? Or, perhaps, are there ways in which an organization can be structured to best take advantage of the alertness of the individuals, especially the managers, who comprise it? I will argue below that the answer to the last question is "yes," and that one key feature of organizations that can take advantage of alertness is the flexibility of their capital structures, including their human capital. Firms that are more flexible are better able to adjust to exogenous change and will be more likely to survive in a more rapidly changing environment. This argument leads us to a third Kirznerian concern that will conclude the paper: the relationship between entrepreneurship and the justification of profits and losses in the market.

\section{Alertness, "Serendipity," and the Firm}

Central to Kirzner's theory of entrepreneurship is the faculty of "alertness." He argues that entrepreneurs are simply more "alert" to possible profit opportunities than others. This faculty of alertness consists in seeing what others have not and thereby taking advantage of opportunities before others do. Kirzner argues that alertness is a psychological propensity, and not a "resource" one owns. Alertness is therefore related to Kirzner's well-known distinction between "search" and "discovery." Deliberate search is where one knows what one is looking for and chooses to invest, or not invest, resources in trying to find the object one desires. By contrast, "discovery" involves surprise in the face of sheer ignorance. When one discovers something, one is surprised because one has found something one did not even know was there to consciously look for. Discovery consists in finding something you did not know you did not know. For example, if one cannot remember a friend's phone number, one can deliberately search for it using a phone book. However, if while doing so one stumbles across the name and number of a long-lost friend who one was not aware had recently moved to the area, that would be a discovery. There was no way to deliberately search for that person's number as one was unaware of one's own ignorance about it.

It may seem, therefore, that discoveries come accidentally and are just a matter of pure luck. If one does not know what is out there to be found, one cannot deliberately search for it, so discoveries must be sheer luck. If so, then how on what basis does one ethically justify the gains of the winners and the losses of losers? ${ }^{1}$ Kirzner's response to this is to deny that blind luck and conscious choice define the whole set of possible explanations. Alertness is a third category. When we are alert to opportunities we are dimly aware that something unexpected might be around the corner so we are, to use Kirzner's phrase, "scanning the horizon" in

1 See Kirzner-1989 for more on these issules. 
order to recognize such opportunities when they arise. It is worth noting that alertness and "horizon scannning" can also be deployed "defensively" as ways of reacting to unexpected negative exogenous change, although this is not something Kirzner discusses at length.

The quality of alertness might be equally well described by the word "serendipity." Though often used as a synonym for "good luck," the dictionary definitions of the word suggest something more subtle. The American Heritage New College Edition defines "serendipity" as "the faculty of making fortunate and unexpected discoveries by accident" and dictionary.com defines it as "accidental sagacity; the faculty of making fortunate discoveries of things you were not looking for." Both definitions seem quite similar to Kir $\measuredangle n e r ' s$ description of alertness, particularly the second with its phrase "things you were not looking for." What is most notable, however, is that both refer to serendipity as a "faculty," suggesting that it can be possessed and perhaps even nurtured in some way. More interesting, referring to it as a faculty seems to be in some tension with the use of the word "accident" in both definitions. If such unexpected discoveries (which may well be redundant) are genuinely "by accident," then how could one describe seredipity as a "faculty" of being able to, as it were, conjure them up? Or, conversely, if one has the faculty of serendipity, then one's discoveries cannot be completely attributed to mere "accident." 2

The question of where alertness or serendipity comes from is one on which Kirzner has been agnostic because it is more properly the province of psychology than economics. Presumably some people are just born with it and others are not, or there are some psychological processes by which individuals can enhance their ability to be alert. In either case. Kirzner would argue that we are not talking about economics. It may well also be the case that certain institutional environments lead people to be more alert to opportunities than they would be otherwise. For example, where profits are heavily taxed and/or losses can be easily written off, social processes will not select for those with higher levels of alertness. 3 As a result, we might expect there to be "less" alertness in such economies. However, the focus on the individual does not exhaust the question of how one might or might not encourage or enhance the faculty of alertness or serendipity.

\footnotetext{
2 The origins of the word are interesting as well: "We are inclebted to the English author Horace Walpole for the word serendipity, which he coined in one of the 3,000 or more letters on which his literary repulation primarily rests. In a letter of Januilsy 28,1754 , Walpole says that this discovery, indeed, is almost of that kind which I call Serendipity, a very expressive word. Walpole formed the word on an old name for Sri Lanka, Serendip. He explained that this nalne wals part of the title of 'a silly fairy tale, called The Three Princes of Serendip: as their highnesses traveled, they wore always making discoveries, by accidents and sagacity, of thing. which they were not in quest of..."." (dictionary. con http//www dictionaliy.com/cgi-bin/dict.pl?ternn=serendipity).

3 This point is clearly related to the Big Players work by Koppl and others. See Konpl (koppl-2002) for an overview. The Big Players literature argues that makets characterized by a Big Player immune to profit and loss will be more chaotic, in that induced variables will not be as closely linked to underlying valiables, than would be the calse without such Big Players. In addlition, Austrians have recognized that entrepreneurial alertness operates to some degree in all institutional contexts, but that some sets of institutions may channel that alertness in ways that are more socially heneficial. Under the Soviet-style economy, being alert may mean taking actvantage of political opportunities in ways that are zero-sum at best, rather than taking advantage of positive-sum maldket opportunities.
} 
When we move away from individuals to organizations, the question of why some firms are better able to seize opportunities and react to exogenous change seems more clearly within the purview of economics. Economics may very well have something to say about what characteristics of organizations make them more or less likely to be entrepreneurial. In reality, turning an insight into action requires two steps: the insight, then some way of operationalizing that insight. Kirzner insists that only the insight qualifies as "entrepreneurship" because once the insight occurs, the problem of making it happen is simply a matter of constrained maximization given the revised (post-insight) framework of means and ends. The entrepreneurial moment is the recognition of the opportunity, and it is for that reason that Kirzner can also argue that entrepreneurship is costless. Genuine discovery is free and individual acts of discovery cannot be "produced" through investment.

The question of whether individuals can turn insight into action might be answered with reference to all sorts of contingent factors: proximity to loanable funds, social networks, bargaining skills, and the like. These factors might all matter within firms as well. However, the collective nature of production in the firm also raises the question of ways in which the internal structure of the firm might make it easier for some firms to turn an individual's recognition of a profit opportunity, or potentially loss-inducing change in the market, into an actual change in their production processes. Can the capital, including human capital, of the firm be marshalled quickly and with minimal cost into a new direction when a new discovery is made? If so, under what circumstances is this more likely? If we can answer this question, then perhaps we can find some ways that also help to explain why some firms do well and others do not that move us beyond "good luck" and "bad luck" and simple "alertncss."

\section{The Firm, Flexible Capital, and Exogenous Change}

Central to the Austrian understanding of the production process is the role of capital. F'or Austrians, capital is best understood using Kirzner's 4 phrase "unfinished plans." Capital represents either an input or intermediary good that is part of an asyet-unfinished plan. This definition of capital is not restricted to material goods. Obviously services and human capital more generally can be subsumed under it, as can intangibles such as good will and reputation. Viewing capital this way enables us to recognize the key feature of capital: its heterogeneity. We cannot treat capital as an undifferentiated lump of "stuff" because the specific plans of which capital goods are a part require spccific sorts of inputs for their execution. Capital is always seen subjectively by producers as concrete goods and services, rather than some "glob" called capital. Even financial capital, which might come the closest to this homogeneity, must be turned into concrete goods and services before the production plan can be fully executed.

\footnotetext{
${ }^{4}$ Kiræner-1996
} 
It is tempting to want to respond by saying that because all capital can be reckoned in terms of moncy that we can add up the value of all inputs to compute an aggregate, and effectively homogenous, measure of capital. The monetary value of all capital would then demonstrate that capital could be understood as an undifferentiate homogenous "fund." However, as Lachmann and others have argued, the only way such a procedure makes sense is if we are in equilibrium. Only in equilibrium is it the case that all production plans are perfcctly consistent with each other, enabling us to assume that each capital good's market vahue accurately reflects its underlying importance. Outside of equilibrium, a capital good's market value may be embued with error if it is part of a production plan that cannot be executed, or will not be executed profitably. It may also be the case that, outside of equilibrium, the same piece of capital figures in the incompatible plans of two different producers. If so, then adding up the value that both producers put on the good will give an erroneous picture of capital as well. Given that real world economies are never in equilibrium, these attempts to construct an aggregate measure of capital, and thus treat it homogenously are theoretically unsound.

Instead, we nced to conceive of capital in terms of the ways in which particular bits of it figure into the particular production plans of entrepreneurs. Once we recognize that capital goods are neither perfectly specific (they do not have only one possible use) nor perfectly general (they cannot be used for any production process), we can talk in terms of the "multiple specificity" of capital. Most capital goods have a number of uses that is greater than one but less than infinity. The problem for producers is to determine which capital goods can be used most profitably in which production processes, given that each process has multiple combinations of capital that can contribute to it and that each piece of capital can likely be used in a variety of production processcs. This is the process of economic calculation, and profit and loss tell the producer something about the expost accuracy of her choices surrounding capital.

Lachmann's terminology 5 of "complementarity" and "substitutability" are useful here as well. In the static world, the complementarity of capital is the key. As the producer envisions a production process, she must bring together capital that is complementary. The inputs must "fit" together to produce the desired output. In the facc of change, however, the crucial issue becomes substitutability. For example, should losses signal the need to change capital combinations, the entrepreneur will be concerned with her ability to substitute one kind of input for another. When contemplating change, the degree to which one piece of capital can be used in place of another is the central consideration.

It is important to note that changing capital combinations is costly. These costs come in two related forms. First, even if capital goods, or labor, has multiple uses, they are not likely to be equally productive at all of those uses. So even if the same input can be used to produce two different outputs, it may be more productive at one than the other, which implies that switching it from the nore to

5 Lichmann-1978 
the less productive use will be costly (in comparison to its higher valued use, or in comparison to a capital good primarily intended to produce the new output). The second sense in which changing capital combinations is costly refers to refitting and retraining costs. Some inputs can only produce other outputs with modifications of some sort. A machine might need some refitting of parts to produce a slightly different output (e.g., moving from producing high-top to lowtop sneakers). In a similar fashion, labor may need to be retrained to adjust to a different production process. In either case, moving inputs with multiple uses to a different use is costly.

This analysis suggests a trade-off facing owners of capital. It is likely that capital that is designed for a very small number of uses will be more productive in those uses than is capital for which that use is one of a larger number of possible uses. More specific capital is likely to be more productive in the process for which it was designed than is more general capital. The trade-off here is that more specific capital will be more costly to refit or retrain in the face of market signals suggesting a new production plan is in order. As with neoclassical theories of the specificity of assets, Austrian capital theory suggests that owners of highly-specific capital goods face signficant losses and/or refitting costs when the goods' outputs fall in market value. Fntrepreneurs and managers must therefore make some very careful decisions about the specificity of their capital goods, including their human capital, when putting together a production plan. In Lachmann's terms, highly complementary capital structures full of very specific capital goods may have very high substitution costs if they turn out to be in error.

One key objective constraint that will affect the way in which entrepreneurs manage this trade-off will be the degree of uncertainty in the marketplace. Clearly, where uncertainty is greater, entrepreneurs may well lean toward the "more flexible" end of the trade-off, in anticipation of the need to react more often and more siginificantly to changes currently unforseeable in their details. Even though our Kirznerian sheer ignorance prevents us from constructing definitive probabilistic distributions of all possible future events, it is within our power to be aware of higher or lower degrees of uncertainty in the market. We may not know precisely what tomorrow will bring, but we can use information from the world around us to say that we are less certain about what tomorrow will bring than we were, say, last week. Faced with facts that create a larger expectation of uncertainty, entrepreneurs will be willing to trade off some of the productivity of more specific inputs for the flexibility provided by capital combinations that can be shuffled around at lower cost (i.e., that are more easily substituted for, even if they are less strongly complementary).

The term "flexibility" might best describe the feature of capital structures that enable them to adjust to exogenous change at relatively low cost. The notion of flexibility can be applied to both individual goods, in which it becomes a close, but more descriptive, synonym for "generality," and to a whole production process or capital structure. In an environment of greater uncertainty, or a faster pace of economic change, entrcpreneurs are likely to prefer, on the margin, capital that has relatively more flexibility. This may be particularly true of human capital, where employces may be required to move quickly from one project or production process to another as market conditions change. The heightened pace of change 
that has defined the last decade or so in the global economy may have caused both firms and individual workers to increase the flexibility of their (human) capital to be prepared for very sudden new demands on them. ${ }^{6}$

Aside from the relative specificity of a firm's capital goods, another element that contributes to the overall flexibility of the firm's capital structure is the sorts of contractual arrangements firms have with their human and non-human capital. Shorter term contracts enhance flexibility, while longer-term ones reduce it. Again, the same sorts of trade-offs arise as we saw with specific and general capital. Longer term contracts might have advantages in terms of lower average costs, or goodwill toward employees, or the reduction of transaction costs. However, they also can lock firms in to particular capital goods or capital/labor mixes, not unlike the ways in which very specific capital goods lock firms into particular production processes. Shorter term contracts will make firms more flexible, but with the costs that go with the losses of the advantages of longer term contracts. These contract issues are particularly important with respect to human capital. The firm's ability to reallocate labor in the face of exogenous change is central to its overall flexibility and the degree of contractual lock-in is a potential barrier to labor reallocation.

The degree of flexibility of a firm's capital structure will be an important factor in its ability to respond to profit opportunities or potentially damaging exogenous change. If the owners or managers of a firm see a new profit opportunity (Kirzner's moment of entrepreneurial insight), it may well require changes in the allocation of the firm's capital to actually grasp the opportunity. Firms that have more flexible capital structures should, ceteris paribus, be more quick to seize such opportunities than those who are more committed to particular production plans through the use of highly specific inputs.

\section{Serendipity Revisited}

The previous section's discussion of capital flexibility and the organization of the firm allows us to revisit our opening discussion of serendipity. If serendipity is the faculty of making fortunate discoveries, then when we think of a firm being serendipitous, it seems reasonable to argue that the flexibility of its capital structure may be a crucial factor in its ability to take advantage when serendipity shows its face. A flexible capital structure cannot explain the moment of insight per se, but it perhaps goes a long way in explaining why some firms are better able to translate such insights into action. Sonetimes we speak of firms being "in a better position"

\footnotetext{
6 This argument is consistent with media reponts about the beliefs of younger workers, where such workers are assuming that they will have to be prepared to take on a series of "careers" racher than spending their lives doing more or less the sinne thing. If more flexible human capital will be more valuable in the conning years, then eriucational institutions that stress widiely-applicable skills such as literacy, numeracy, and eritical thinking (ralkler than prolessional training), and inculeate the alvility to recognize, welcome, and respond to change will he hetrer preparing their graduates for the realities of the 21 st century labor market.
} 
to take advantage of an entrepreneurial insight, but this is not quite the same point. The notion of "being" in a better position seems a bit too static to capture the broader issue. It is not just that a firm is already structured in a way such that when the opportunity is seen it is ready to produce. Rather, there is the more dynamic question of how and why some firms can react to noticed opportunites more quickly than others. It is not that an opportunity "tailor made" for their current organizational structure suddenly appeared. Instead, it is a question of seeing how a current structure can be transformed at low cost into a different structure that could turn the noticed opportunity into real action.

This gives us another way to navigate the waters between blind luck and conscious search. Alertness gets us part of the way there, but again it must be turned into action. Firms that have a high degree of flexibility in their capital structures will be better able to turn alertness into profit. It is not blind luck, nor is it the case that the entrepreneurial insight finds the firm "ready and waiting" to take advantage of it, rather the firm can react to the noticed opportunity because it has organized itself in a way that enables it to be prepared to do so.

\section{Reacting to Negative Exogenous Change}

In many ways, this is familiar Kirznerian ground. However, a less wellploughed set of questions are those that relate to negative exogenous change. That is, how do firms react when their markets contract, or completely disappear? In one sense, this is just the obverse of being alert to a profit opportunity as contraction in one area would seem to suggest profit is available elsewhere. Nontheless, we can perhaps conceive of examples where the exogenous change is so pervasive as to affect many areas of the economy in a variety of ways. In fact, we perhaps need not be very imaginative here, as the attacks of September 11, 2001 might provide an instructive example.

Some observers have commented that the economic damage wreaked on a variety of firms in the wake of the attacks has been a matter of collosal bad luck. That is, firms that have lost millions or billions since then (for example, travel and tourism related firms) are simply the victims of bad luck. It was their bad luck to be in the wrong industry at the wrong time. It is interesting to see the media portray these firms as "victims." It would seem that when firms are making profits they are the victimizers but when they are making losses they are the victimized. This suggests that firms are active agents when they are making profits, but are passive recipients of the economic "deal of the cards" when they are making losses. From a Kirznerian perspective, this asymmetry in treatment makes no sense. Both profits and losses emerge from the active choices that firms make. If losses are signals that profits are available elsewhere, the choice to have pursued the path that generated losses, and not to switch paths in the face of such losses, are no less active choices than the one that would have produced positive profits in the first place.

But, runs the objection, are not the events of September 11 in an entirely different category? Surely those firms who are seeing massive losses are seeing them through no fault of their own. They did not orchestrate or execute the 
terrorist attacks and surely they could not be expected to have forseen such an event. All of this is true to some extent. However, if we wish to explain why some firms are seeing greater losses than others, and if we wish to understand why some firms might better able to survive an event of this sort, we will have to move beyond treating firms as passive victims of exogenous change.

Firms that survive these sorts of events will be those that are best able to make quick adjustments to the new reality. For example, airlines that had the flexibility to move or cut flights quickly, or to layoff or cut workers, would see a smaller negative effect. Airlines that used fleets that were maximally flexible would also be in relatively better shape. For example, firms that were able to use smaller, more fuel-efficient, planes on routes that were losing significant ridership did better than those that had fewer of such planes that they could shift around in their route structure. One could make similar arguments about the sorts of hub-andspoke routing that airlincs use. Those firms with sufficient flexibility to replace non-stops with more efficient connecting flights were likely to do relatively better. It will not just be blind luck as to which firms are hit hardest and which are not, at least over something other than the immediate run.

It is worth noting in this context the role played by the US government's subsidies to the airlines in the wake of Scptember 11. Not only did such monies reduce the immediate incentive to make the necessary adjustments to the new underlying variables, but it sets a dangerous precedent for parallel situations in the fulure. If airlines, or any firm for that matter, expect to get a cash infusion in the face of events that causc a widespread and significant loss of their business, they are that much less likely to create the sorts of capital structures that would enable them to react appropriately to such losses. Absent capital structures of greater flexibility, the losses from similar events in the future might well be greater than they would have been had the subsidy not taken place the first time around. Given that less flexible structures may be more efficient at any point in time, firms might well accept the risk of a lack of flexibility if they expect to be bailed out if their gamble backfires on them. In a classic example of moral hazard, the subsidy creates an incentive to do precisely the wrong things that would be necessary to avoid the argument for such subsidies in the future. ${ }^{7}$

The losses generated by a pervasive and negative cxogenous change such as the one under discussion are a signalling process that should not be shortcircuited. Although it is certainly unfortunate that so many have been so adversely affected by the attacks-induced changes, those changes are necessary and appropriate given the events. The destruction of physical capital will always bring economic contraction in its wake, and the shifts in public preferences that have followed (e.g., from leisure travel to staying home, or from business travel to leleconferencing) will have major transitional consequences. Those adverse effects reflect real events. The losses that fims suffer in the transition are no less real, or no less reflective of "victimhood," than are the profits they reaped clue to economywide increases in productivity due to technological advances of the last decade.

7 From a public choice perspective, this argument might be at grood reason for airlines to have foblobed for the bailout in the first place. It prevents them from having to malse costly aljustanents to their behavior. 
Firms with the flexibility to absorb and adapt to the new technologies profited from it. And now firms with the flexibility to adjust to the new underlying economic reality will do better by it. Entrepreneurial profits and. losses that reflect the degree of adjustment to underlying changes are, in Kirzner's phrase, the driving force of the market. Just as those who understand the value of entrepreneurship are prepared to use its beneficial social effects to justify the profits of those who make discoveries, so must we be prepared to tolerate the losses that go with wrenching exogenous change for precisely the same reasons. In both cases we must continue to strive to understand how and why some firms are better able to respond to those changes, and why some are not.

\section{Conclusion}

This paper has attempted to take two of the areas of analysis to which Israel Kirzner made major contributions and explore how they interrerlate and can be applied to a third area of Kirzner's concern - the social role and ethical status of market profits. The question of why some firms are better able to turn their entrepreneurial alertness into profitable action led us to explore in a preliminary way some organizational features of the firm that might be responsible for their ability to react. In particular, we argued that the flexibility of the firm's capital structure will be, ceteris paribus, directly related to its ability to respond to both profit opportunities and negative exogenous changes. Austrian capital theory's emphasis on the multiple specificity of capital gives us a good theoretical language to talk about capital flexibility and entrepreneurship. To the degree that the flexibility of a firm's capital structure helps understand why it is better able to react to changes in the underlying variables, it explains why entrepreneurial profits are not simply "good luck" and why losses in the face of even the most unexpected exogenous change (such as that of September 11, 2001), cannot be explained as just "bad luck." The internal organization of the firm may well have much to do with the ability of firms to react to either case.

Israel Kirzner's contributions to the theory of entrepreneurship and capital theory provide us with insights central to our positive understanding of the market economy and our normative evaluation of the results it produces. With his retirement, one of the most incisive and articulate voices of 20th century economics has left the scene. His work that remains will continue to inspire and challenge generations of theorists as well as reminding us of the value of the market economy and the liberal order more broadly. Those who wish to find ways to lift the masses of humanity out of poverty and encourage ongoing human development will long be in his debt. 


\section{References}

Kirzner, I.M. (1989) Discovery, Capitalism, and Distributive Justice, New York, Blackwell.

Kirzner, I.M. (1996) Essays on Capital and Interest: An Austrian Perspective, Cheltenham, UK, Edward Elgar.

Koppl, R. (2002) Big Players and the Economic Theory of Expectations, New York, Palgrave.

Lachmann, L. (1978) Capital and its Structure, Kansas City, Sheed Andrews and McMeel. 